\title{
Pemodelan Tinggi dan Waktu Tempuh Gelombang Tsunami Berdasarkan Data Historis Gempa Bumi Bengkulu 4 Juni 2000 di Pesisir Pantai Bengkulu
}

\author{
Rahmad Aperus ${ }^{1, *}$, Dwi Pujiastuti ${ }^{1}$, Rachmad Billyanto ${ }^{2}$ \\ Jurusan Fisika, Universitas Andalas ${ }^{1}$ \\ Badan Meteorologi Klimatologi dan Geofisika (BMKG), Padang Panjang ${ }^{2}$ \\ *rahmadaperus@gmail.com
}

\begin{abstract}
ABSTRAK
Telah dilakukan pemodelan tinggi dan waktu tempuh gelombang tsunami di pesisir pantai Bengkulu dengan menggunakan software L-2008 dan Travel Time Tsunami (TTT). Dalam penelitian ini digunakan data historis gempa bumi Bengkulu 4 Juni 2000 dengan skenario magnitudo $8 M_{w}, 8,5 M_{w}$ dan $9 M_{w}$. Daerah dampak tsunami yang diamati adalah Muko-Muko, Ketaun, Kota Bengkulu, Mana dan Kaur. Dari hasil pemodelan diperoleh bahwa daerah yang paling cepat dihantam tsunami adalah daerah Mana dengan waktu 20 menit 7 detik. Nilai run up tsunami tertinggi juga berada di daerah Mana. Nilai run up yang diperoleh dari hasil pemodelan menggunakan skenario magnitude $8 \mathrm{M}_{\mathrm{w}}$ adalah $2,01 \mathrm{~m}$, skenario magnitudo 8,5 $\mathrm{M}_{\mathrm{w}}$ adalah 4,05 $\mathrm{m}$ dan skenario magnitudo $9 \mathrm{M}_{\mathrm{w}}$ adalah $9,31 \mathrm{~m}$.
\end{abstract}

Kata kunci: tsunami, pemodelan, software L-2008, software TTT, run up

\section{ABSTRACT}

Modelling of height and travel time of tsunami's wave has been done on the coast of Bengkulu using software L-2008 and Travel Time Tsunami (TTT). In this research used earthquake historical data in Bengkulu on June 4, 2000 using magnitude scenario of $8 M_{w}, 8.5 M_{w}$ and $9 M_{w}$. The tsunami impacted region observed is Muko-muko, Ketaun, Bengkulu City, Mana and Kaur. From the modelling result obtained that the quickest area impacted by the tsunami is Mana area which is 20 minutes 7 seconds. The higest tsunami run up value is also located in Mana area. The run up value obtained from modelling result using magnitude scenario of $8 M_{w}$ is $2.01 \mathrm{~m}$, the magnitude scenario of $8.5 M_{w}$ is $4.05 \mathrm{~m}$ and the magnitude scenario of $9 M_{w}$ is $9.31 \mathrm{~m}$.

Keywords: tsunami, modelling, software L-2008, software TTT, run up:

\section{PENDAHULUAN}

Zona subduksi merupakan wilayah yang sering melepaskan energi gempa bumi yang dapat membangkitkan gelombang tsunami. Berdasarkan catatan sejarah gempa bumi besar pernah terjadi di sebelah selatan khatulistiwa tahun 1833 berkekuatan 8,9 SR dan tahun 1797 berkekuatan 8,3 SR mengakibatkan tsunami yang menghantam Sumatera Barat dan Bengkulu. Para ahli memprediksi bahwa zona subduksi akan menghasilkan gempa bumi besar kembali dengan periode ulang 200 tahunan (Natawidjaja, 2007). Pada tanggal 4 Juni 2000, terjadi gempa bumi berepisenter di zona subduksi dengan kekuatan 7,3 SR yang menggoncang Bengkulu. Tanggal 26 Desember 2004 gempa bumi berkekuatan 9,2 SR yang memicu terjadinya tsunami terparah pada abad ini menghantam daratan Aceh. Tanggal 12 September 2007 kembali terjadi gempa bumi berepisenter di zona subduksi berkekuatan 7,9 SR juga memicu tsunami yang melanda daratan Bengkulu (BMKG, 2014).

Berdasarkan catatan sejarah gempa bumi di Pulau Sumatera, wilayah Bengkulu memiliki potensi gempa bumi besar dan dapat membangkitkan gelombang tsunami. Menurut penelitian Ardiansyah (2014), wilayah Bengkulu dan sekitarnya masih memiliki akumulasi stress yang tinggi setelah kejadian gempa bumi 4 Juni 2000 dan 12 September 2007 yang suatu waktu bisa dilepaskan dalam bentuk gempa bumi yang dahsyat. Wilayah Bengkulu khususnya di wilayah rupture zone gempa bumi 12 September 2007 memiliki tingkat kerapuhan batuan yang rendah dan berpeluang terjadinya gempa bumi besar di waktu yang akan datang. Wilayah pesisir barat Bengkulu berbentuk teluk dan pantai yang landai, apabila terjadi gempa bumi besar maka wilayah tersebut berpotensi dilanda gelombang tsunami dengan tingkat kerusakan yang tinggi. Sebagian besar penduduk dengan populasi yang cukup padat bermukim di pesisir pantai. Oleh karena itu, perlu dilakukan penelitian tsunami di wilayah Bengkulu dalam upaya mitigasi bencana. 
Terdapat banyak software pemodelan tsunami, diantaranya adalah WinITDB, AWI, AVINAMI, TURMINA, TUNAMI, L-2008 dan TTT (Sunarjo dkk., 2010). Pemodelan tsunami dengan menggunakan software L-2008 pernah dilakukan oleh Setyonegoro dkk. (2012). Setyonegoro dkk. (2012) melakukan penelitian untuk memodelkan gempa bumi dan tsunami Mentawai 25 Oktober 2015 dan diperoleh hasil pemodelan tinggi gelombang tsunami sampai ke daratan (run up) dan run up survei lapangan relatif sama. Pemodelan tsunami dengan software TUNAMI N-2 untuk menentukan tinggi tsunami dan software Travel Time Tsunami (TTT) untuk menentukan waktu tempuh gelombang tsunami juga pernah dilakukan oleh Pribadi (2008). Pribadi (2008) melakukan pemodelan dengan menggunakan data gempa bumi Bengkulu tahun 1833. Hasil penelitian ini adalah gelombang tsunami paling tinggi berada di Kota Bengkulu $(4,53 \mathrm{~m})$ dan daerah paling cepat dihantam oleh gelombang tsunami adalah daerah Muara Bunga (15 menit 34 detik).

Dalam penelitian ini digunakan software L-2008 untuk memodelkan run up tsunami dan software TTT untuk memodelkan waktu tempuh gelombang tsunami. Data yang digunakan pemodelan ini adalah data gempa bumi yang terjadi di Bengkulu pada tanggal 4 Juni 2000 dengan menggunakan skenario magnitudo $8 \mathrm{M}_{\mathrm{w}}, 8,5 \mathrm{M}_{\mathrm{w}}$ dan $9 \mathrm{M}_{\mathrm{w}}$.

\section{METODE}

Data yang digunakan dalam penelitian ini adalah data sekunder dari BMKG (Badan Meteorologi Klimatologi Geofisika) sebagai data parameter sumber gempa bumi, USGS (United Stated Geological Survey) sebagai data parameter bidang sesar dan NOAA (National Oceanic and Atmospheric Administration) sebagai data batimetri.

\subsection{Data parameter sumber gempa bumi}

Data historis gempa bumi yang digunakan dalam penelitian ini adalah gempa bumi Bengkulu 4 Juni 2000 yang diperoleh dari BMKG (2014). Parameter sumber gempa bumi 4 Juni 2000 diantaranya adalah waktu terjadinya gempa bumi pada pukul 16:28:24, episenter gempa bumi terletak pada koordinat $4,70^{\circ} \mathrm{LS}$ dan $102^{\circ} \mathrm{BT}$, hiposenter gempa bumi $33 \mathrm{~km}$ dari permukaan laut dan kekuatan magnitudo gempa bumi sebesar 7,6 $\mathrm{M}_{\mathrm{w}}$.

\subsection{Data parameter bidang sesar}

Data parameter bidang sesar yang digunakan dalam penelitian ini adalah data historis sumber gempa bumi Bengkulu 4 Juni 2000 yang diperoleh dari USGS (2015). Data parameter bidang sesar berupa panjang sesar $(A l)$ dan lebar sesar $(A w)$, strike, dip dan slip. Nilai parameter bidang sesar adalah strike $=192^{\circ}$, dip $=46^{\circ}$ dan slip $=50^{\circ}$, sedangkan nilai $A l$ dan $A w$ dihitung dengan mengkonversi nilai masing-masing magnitudo gempa bumi.

\subsection{Data batimetri}

Data batimetri yang digunakan dalam penelitian diperoleh dari situs NOAA (National Oceanic and Atmospheric Administration) berupa data etopo2. Batasan grid batimetri penelitian terletak pada koordinat $0^{\circ} \mathrm{L}-10^{\circ} \mathrm{LS}$ dan $93^{\circ} \mathrm{BT}-103^{\circ} \mathrm{BT}$ (NOAA, 2016).

Pemodelan tsunami dalam penelitian ini dilakukan dengan menggunakan software L2008 dan TTT. Tahap-tahap penelitian yang dilakukan adalah:

1. Menentukan data historis gempa bumi dan daerah penelitian.

Data historis gempa bumi yang digunakan adalah gempa bumi Bengkulu 4 Juni 2000 dan 12 September 2007 berepisenter di zona subduksi. Daerah penelitian berada di Provinsi Bengkulu dapat dilihat pada Gambar 1.

2. Menentukan pemodelan tsunami.

3. Mengunduh data batimetri dan membuat peta batimetri pantai Bengkulu.

4. Menentukan deformasi sumber gempa bumi dengan mengkonversi nilai parameter sumber gempa bumi dan parameter bidang sesar.

5. Menentukan pemodelan run up tsunami di daerah pengamatan.

6. Menentukan waktu tempuh gelombang tsunami di titik-titik pengamatan 


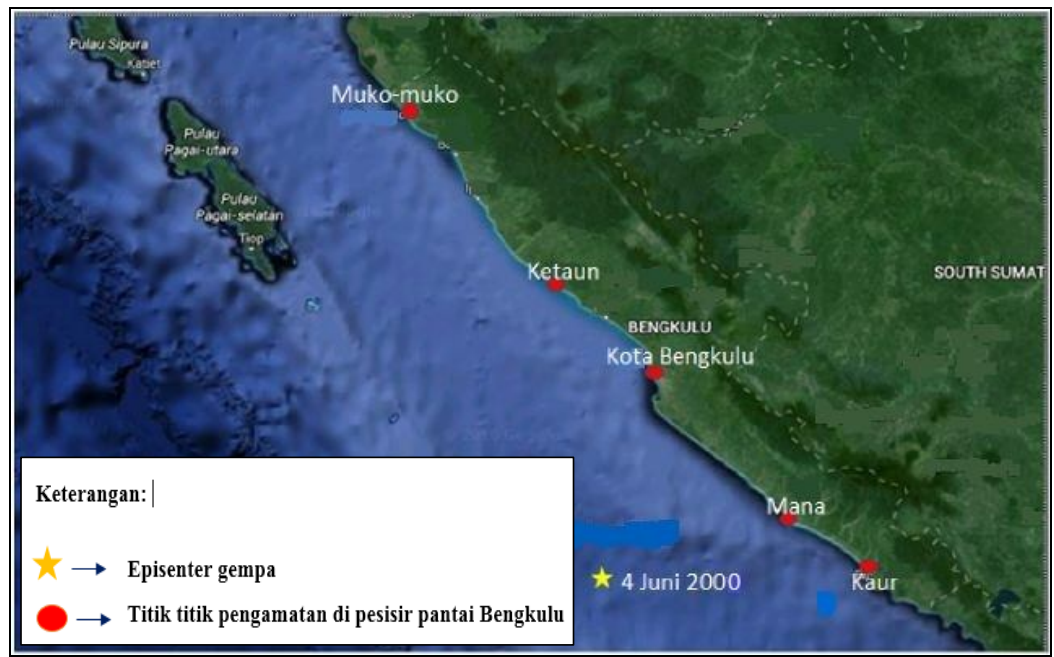

Gambar 1 Daerah Penelitian

\section{HASIL DAN DISKUSI}

\subsection{Peta Batimetri Wilayah Perairan Bengkulu}

Hasil dari pembuatan peta batimetri wilayah perairan Bengkulu dapat dilihat pada Gambar 2. Gambar 2 menunjukkan bahwa kondisi batimetri perairan Bengkulu memiliki perbedaan kedalaman laut. Hal ini dapat dilihat dari perbedaan warna pada peta dan nilai pada legenda peta. Nilai negatif menunjukkan daerah daratan, sedangkan nilai positif menunjukkan daerah perairan. Daerah perairan bagian utara memiliki kedalaman laut yang lebih dangkal, ditunjukkan dengan peta berwarna biru muda. Sedangkan perairan bagian barat daya memiliki kedalaman laut yang lebih dalam ditunjukkan dengan peta berwarna ungu. Kedalaman laut wilayah perairan Bengkulu berkisar 1296 m sampai 6484 m dengan kedalaman laut terdangkal adalah $1296 \mathrm{~m}$ dan kedalaman laut terdalam adalah $6484 \mathrm{~m}$.

Apabila terjadi gelombang tsunami, maka gelombang tsunami memiliki kecepatan lebih besar di perairan berwarna ungu dan memiliki ketinggian lebih tinggi di perairan dangkal berwarna biru muda. Batas antara perairan dangkal berwarna ungu dan perairan dalam berwarna biru muda merupakan zona subduksi. Pada penelitian ini, episenter gempa bumi Bengkulu 4 Juni 2000 berada pada zona subduksi dan perairan dangkal.

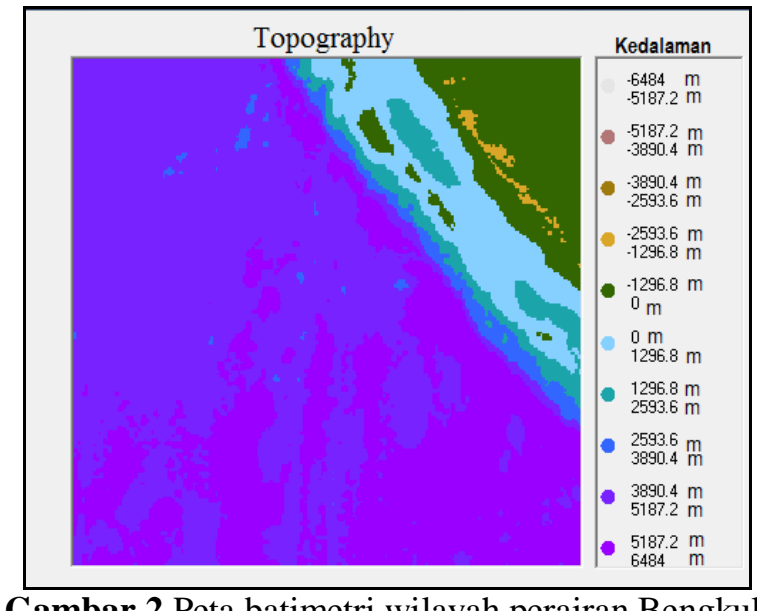

\subsection{Pemodelan Tsunami Menggunakan Data Gempa Bumi Bengkulu 4 Juni 2000}

Pemodelan tsunami menggunakan data gempa bumi Bengkulu 4 Juni 2000 bertujuan untuk mengestimasi nilai run up tsunami yang terjadi dari episenter menggunakan magnitudo gempa bumi $8 \mathrm{M}_{\mathrm{w}}, 8,5 \mathrm{M}_{\mathrm{w}}$ dan $9 \mathrm{M}_{\mathrm{w}}$. Pada pemodelan tsunami ini juga dimodelkan jenis sesar mendatar pada saat kejadian gempa bumi menjadi jenis sesar naik, perubahan jenis sesar ini 
dapat terjadi karena episenter gempa berada pada zona subduksi yang didominasi oleh sesar naik. Nilai masukan sesar pada software L-2008 dimodelkan menjadi sesar naik dengan strike dan dip sesar, yaitu strike $=327^{\circ}$ dan dip $=12^{\circ}$.

\subsubsection{Skenario Pemodelan Deformasi Vertikal Sumber Gempa Bumi Bengkulu 4 Juni 2000}

Hasil pemodelan deformasi vertikal (vertical displacement) sumber gempa bumi Bengkulu 4 Juni 2000 dengan skenario $8 \mathrm{M}_{\mathrm{w}}, 8,5 \mathrm{M}_{\mathrm{w}}$ dan $9 \mathrm{M}_{\mathrm{w}}$ dapat dilihat pada Gambar 3. Gambar 3 merupakan hasil model deformasi vertikal sumber gempa bumi Bengkulu 4 Juni 2000 skenario magnitudo $8 \mathrm{M}_{\mathrm{w}}, 8,5 \mathrm{M}_{\mathrm{w}}$ dan $9 \mathrm{M}_{\mathrm{w}}$ di dasar laut. Pada skenario magnitudo $8 \mathrm{M}_{\mathrm{w}}$ deformasi vertikal bernilai minimum sebesar $-2,13 \mathrm{~m}$ dan nilai maksimum 2,13 $\mathrm{m}$ dengan nilai luasan sesar $7762,471 \mathrm{~km}^{2}$. Pada skenario magnitudo $8,5 \mathrm{M}_{\mathrm{w}}$ deformasi vertikal bernilai minimum sebesar $-3,97 \mathrm{~m}$ dan nilai minimum 3,97 m dengan nilai luasan sesar $24266,10 \mathrm{~km}^{2}$. Pada skenario magnitudo $9 \mathrm{M}_{\mathrm{w}}$ deformasi vertikal bernilai minimum sebesar -7,33 $\mathrm{m}$ dan nilai maksimum 7,33 m dengan nilai luasan sesar $75857,76 \mathrm{~km}^{2}$. Nilai deformasi vertikal sumber gempa bumi setiap magnitudo berbeda-beda. Semakin besar mgnitudo maka semakin besar pula nilai deformasi vertikal sumber gempa bumi.
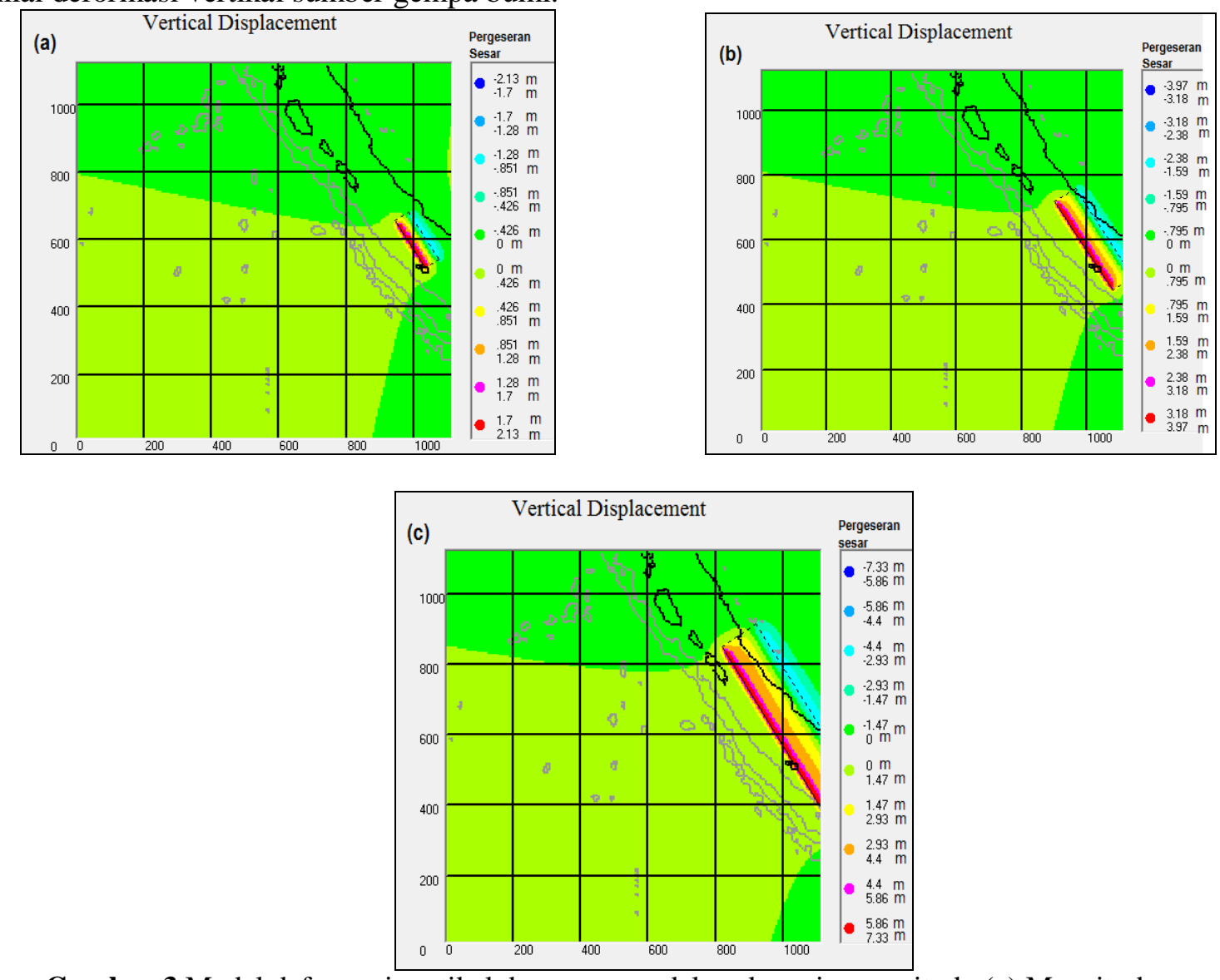

Gambar 3 Model deformasi vertikal dengan pemodelan skenario magnitudo (a) Magnitudo $8 \mathrm{M}_{\mathrm{w}}$ (b) Magnitudo 8,5 $\mathrm{M}_{\mathrm{w}}$ (c) Magnitudo $9 \mathrm{M}_{\mathrm{w}}$

\subsubsection{Skenario Pemodelan Run Up Tsunami Bengkulu 4 Juni 2000}

Parameter data masukan software L-2008 dari pemodelan run up adalah data batimetri, parameter sumber gempa bumi dan parameter sesar. Hasil pemodelan nilai run up maksimum tsunami Bengkulu 4 Juni 2000 dengan skenario magnitudo $8 \mathrm{M}_{\mathrm{w}}, 8,5 \mathrm{M}_{\mathrm{w}}$ dan $9 \mathrm{M}_{\mathrm{w}}$ dapat dilihat pada Gambar 4. Gambar 4 menunjukkan bahwa pada skenario magnitudo $8 \mathrm{M}_{\mathrm{w}}$ diperoleh nilai run up maksimum bernilai 4,4 $\mathrm{m}$. Pada magnitudo $8,5 \mathrm{M}_{\mathrm{w}}$ diperoleh nilai run up maksimum bernilai 8,98 m. Pada skenario magnitudo $9 \mathrm{M}_{\mathrm{w}}$ diperoleh nilai run up maksimum bernilai 10,3 $\mathrm{m}$. Run up tsunami dipengaruhi oleh magnitudo gempa bumi. Semakin besar magnitudo maka semakin tinggi pula nilai run up tsunami yang dihasilkan di pesisir pantai. Hal ini juga 
disebabkan oleh semakin besarnya nilai magnitudo momen dan semakin luas bidang sesar gempa bumi sehingga magnitudo semakin besar. Nilai run up juga dipengaruhi oleh kondisi batimetri, nilai run up tsunami akan meningkat pada kondisi batimetri perairan laut dangkal dan memiliki teluk.
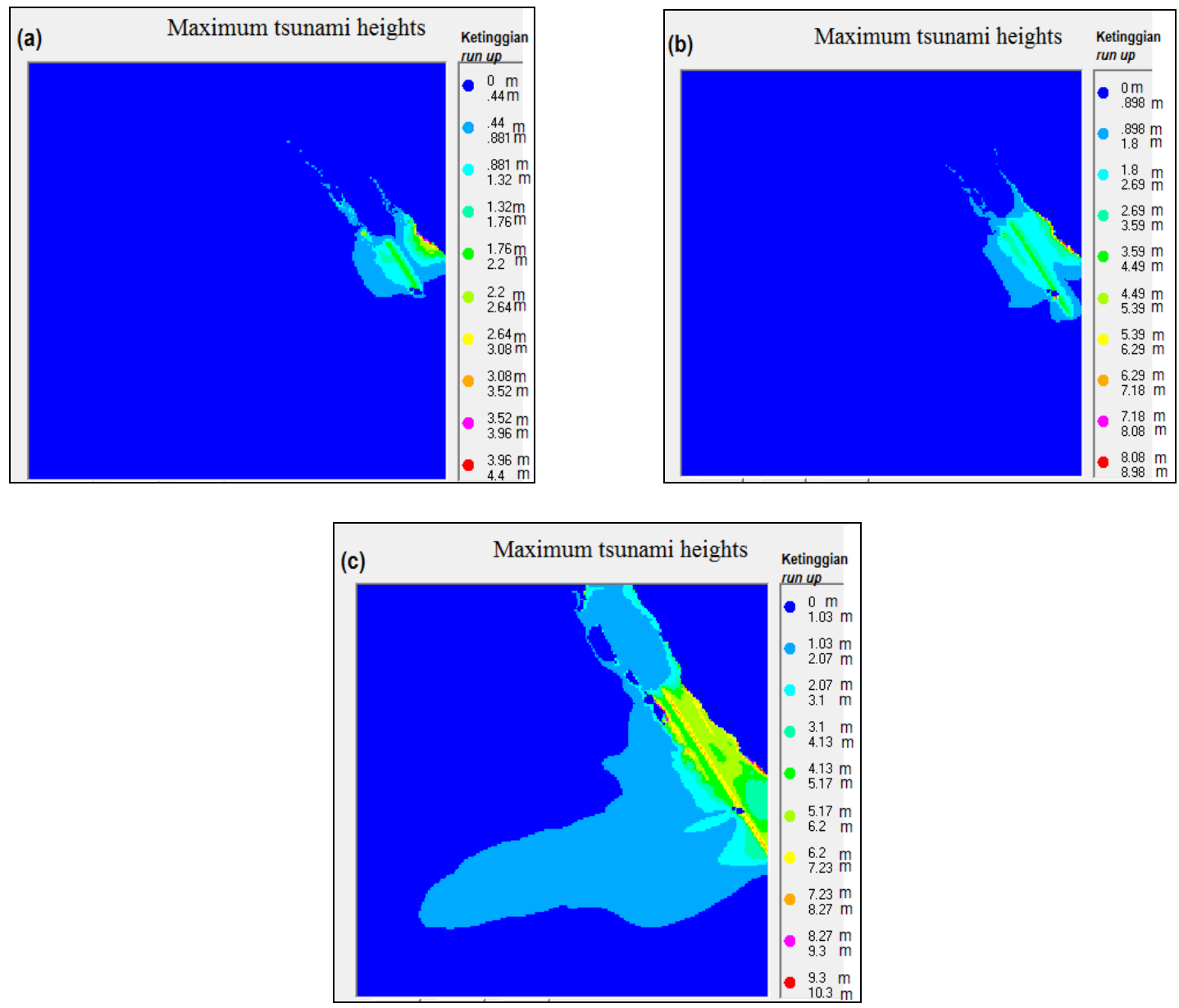

Gambar 4 Model run up maksimum dengan skenario magnitudo (a) Magnitudo $8 \mathrm{M}_{\mathrm{w}}$ (b) Magnitudo 8,5 $\mathrm{M}_{\mathrm{w}}$ (c) Magnitudo $9 \mathrm{M}_{\mathrm{w}}$

Hasil pemodelan nilai run up tsunami Bengkulu 4 Juni 2000 ke titik-titik pengamatan dengan skenario magnitudo $8 \mathrm{M}_{\mathrm{w}}, 8,5 \mathrm{M}_{\mathrm{w}}$ dan $9 \mathrm{M}_{\mathrm{w}}$ dapat dilihat pada Tabel 1. Tabel 1 menunjukkan bahwa hasil pemodelan run up tsunami dengan skenario magnitudo $8 \mathrm{M}_{\mathrm{w}}, 8,5$ $\mathrm{M}_{\mathrm{w}}$ dan $9 \mathrm{M}_{\mathrm{w}}$. Pada skenario magnitudo $8 \mathrm{M}_{\mathrm{w}}$ diperoleh nilai run up tertinggi 2,01 $\mathrm{m}$ dan terendah 0,20 m. Pada skenario magnitudo 8,5 $\mathrm{M}_{\mathrm{w}}$ diperoleh run up tertinggi 4,05 $\mathrm{m}$ dan terendah $1,13 \mathrm{~m}$. Pada skenario magnitudo $9 \mathrm{M}_{\mathrm{w}}$ diperoleh run up tertinggi 9,31 dan terendah 6,02 m. Nilai run up tertinggi terdapat di daerah Mana dan terendah di daerah Muko-Muko. Daerah Mana memiliki nilai run up tertinggi pada setiap skenario magnitudo disebabkan karena daerah Mana berada dekat dengan episenter gempa bumi (Gambar 1) dan juga memiliki daerah berbentuk teluk. Daerah berbentuk teluk menyebabkan sifat gelombang tsunami menjadi kuat, saling terpantul dan terinterferensi (tergabung) menjadi gelombang yang besar sehingga kekuatan gelombang akan terfokus pada teluk tersebut. Akibatnya daerah Mana terkena limpasan gelombang yang lebih besar dibandingkan dengan pantai yang rata. 
Tabel 1 Nilai pemodelan run up tsunami dengan skenario magnitudo

\begin{tabular}{lccccc}
\hline \multirow{2}{*}{$\begin{array}{c}\text { Lokasi titik } \\
\text { pengamatan }\end{array}$} & \multicolumn{2}{c}{ Koordinat } & \multicolumn{2}{c}{ Skenario Magnitudo / run up } \\
\cline { 2 - 6 } & Lintang & Bujur & $\mathbf{8 ~ M}_{\mathbf{w}}$ & $\mathbf{8 . 5 ~ \mathbf { M } _ { \mathbf { w } }}$ & $\mathbf{9 ~ M ~}_{\mathbf{w}}$ \\
\hline Muko-Muko & $2,57^{\circ} \mathrm{LS}$ & $101,10^{\circ} \mathrm{BT}$ & $0,20 \mathrm{~m}$ & $1,13 \mathrm{~m}$ & $6,02 \mathrm{~m}$ \\
Ketaun & $3,38^{\circ} \mathrm{LS}$ & $101,80^{\circ} \mathrm{BT}$ & $0,42 \mathrm{~m}$ & $2,13 \mathrm{~m}$ & $6,60 \mathrm{~m}$ \\
Kota Bengkulu & $3,79^{\circ} \mathrm{LS}$ & $102,24^{\circ} \mathrm{BT}$ & $1,97 \mathrm{~m}$ & $3,66 \mathrm{~m}$ & $7,33 \mathrm{~m}$ \\
Mana & $4,48^{\circ} \mathrm{LS}$ & $102,90^{\circ} \mathrm{BT}$ & $2,01 \mathrm{~m}$ & $4,05 \mathrm{~m}$ & $9,31 \mathrm{~m}$ \\
Kaur & $4,50^{\circ} \mathrm{LS}$ & $103,26^{\circ} \mathrm{BT}$ & $1,23 \mathrm{~m}$ & $3,41 \mathrm{~m}$ & $6,56 \mathrm{~m}$ \\
\hline
\end{tabular}

\subsubsection{Pemodelan Waktu Tempuh Gelombang Tsunami Bengkulu 4 Juni 2000}

Pemodelan waktu tempuh gelombang tsunami Bengkulu 4 Juni 2000 menggunakan software TTT dengan data masukan berupa berupa data batimetri, koordinat lintang dan bujur episenter, serta titik-titik pengamatan. Software TTT hanya dapat memodelkan waktu tempuh gelombang tsunami berdasarkan episenter gempa bumi dan tidak dapat dilakukan pemodelan berdasarkan skenario magnitudo gempa bumi. Hasil pengolahan waktu penjalaran gelombang tsunami Bengkulu 4 Juni 2000 dapat dilihat pada Gambar 5.

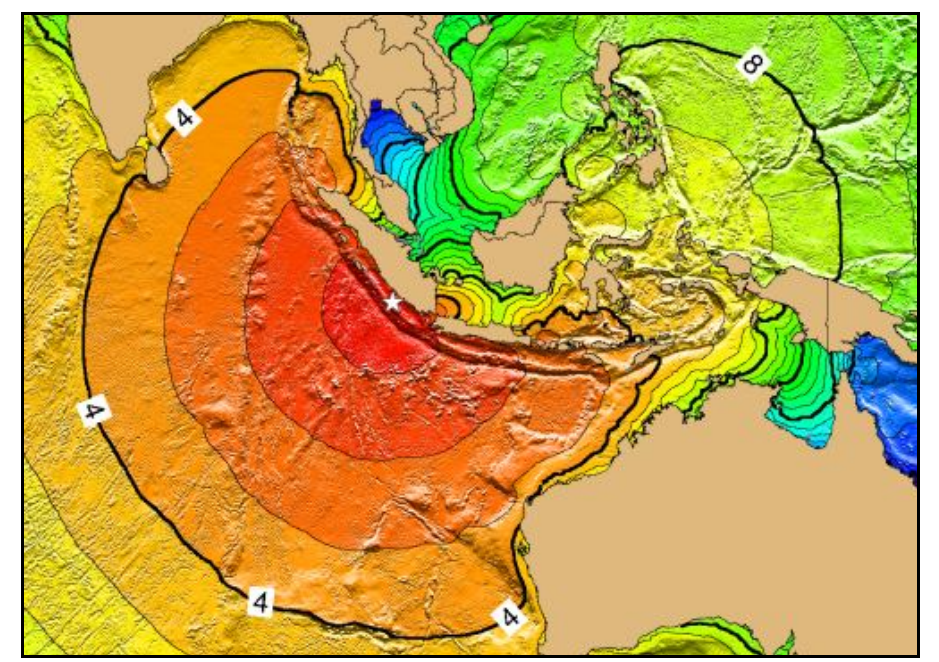

Gambar 5 Waktu penjalaran gelombang tsunami Bengkulu 4 Juni 2000

Gambar 5 merupakan waktu penjalaran gelombang tsunami dengan episenter gempa bumi ditunjukkan dengan tanda bintang. Berdasarkan Prinsip Huygens, gelombang tsunami menjalar berupa gelombang bola sekunder yang digambarkan dengan garis-garis melingkar. Gelombang tsunami menjalar menuju pesisir pantai mengakibatkan terjadi refleksi, refraksi dan difraksi gelombang saat memasuki selat, tanjung dan teluk. Sebagian gelombang tsunami menjalar ke laut lepas dengan jarak yang cukup jauh dalam waktu cukup lama. Angka 4 dan 8 menunjukkan waktu penjalaran tsunami selama 4 jam dan 8 jam.

Hasil pemodelan waktu tempuh gelombang tsunami Bengkulu 4 Juni 2000 titik-titik pengamatan dapat dilihat pada Tabel 2. Tabel 2 menunjukkan bahwa waktu tempuh gelombang tsunami Bengkulu 4 Juni 2000 menuju titik lokasi pengamatan. Waktu tempuh gelombang tsunami sampai di Muko-Muko selama 46 menit 25 detik, Ketaun selama 32 menit 51 detik, Kota Bengkulu selama 24 menit 33 detik, Mana selama 20 menit 7 detik dan Kaur selama 33 menit 8 detik. Waktu tercepat dihantam oleh gelombang tsunami adalah daerah Mana, hal ini karenakan Mana berada dekat dengan episenter gempa bumi Bengkulu 4 Juni 2000 (Gambar 1), sehingga waktu penjalaran tsunami semakin singkat. Waktu penjalaran tsunami paling lama dihantam oleh gelombang tsunami adalah Muko-Muko. 
Tabel 2 Waktu tempuh gelombang tsunami ke lokasi titik-titik pengamatan

\begin{tabular}{llcc}
\hline \multicolumn{1}{c}{$\begin{array}{c}\text { Lokasi titik } \\
\text { pengamatan }\end{array}$} & \multicolumn{2}{c}{ Koordinat } & $\begin{array}{c}\text { Waktu tempuh } \\
\text { gelombang tsunami }\end{array}$ \\
\cline { 2 - 3 } Muko-Muko & Lintang & Bujur & geman \\
Ketaun & $2,57^{\circ} \mathrm{LS}$ & $101,10^{\circ} \mathrm{BT}$ & 46 menit 25 detik \\
Kota Bengkulu & $3,38^{\circ} \mathrm{LS}$ & $101,80^{\circ} \mathrm{BT}$ & 32 menit 51 detik \\
Mana & $3,79^{\circ} \mathrm{LS}$ & $102,24^{\circ} \mathrm{BT}$ & 24 menit 33 detik \\
Kaur & $4,48^{\circ} \mathrm{LS}$ & $102,90^{\circ} \mathrm{BT}$ & 20 menit 7 detik \\
\hline
\end{tabular}

\section{KESIMPULAN}

Dari pemodelan tsunami dengan menggunakan episenter gempa bumi Bengkulu 4 Juni 2000 menggunakan skenario magnitudo gempa $8 \mathrm{M}_{\mathrm{w}}, 8,5 \mathrm{M}_{\mathrm{w}}$ dan $9 \mathrm{M}_{\mathrm{w}}$ diperoleh hasil bahwa nilai run up tertinggi berada di daerah Mana. Nilai run up di daerah Mana menggunakan skenario magnitudo $8 \mathrm{M}_{\mathrm{w}}$ adalah 2,01 $\mathrm{m}$, skenario magnitudo $8,5 \mathrm{M}_{\mathrm{w}}$ adalah 4,05 $\mathrm{m}$ dan skenario magnitudo $9 \mathbf{M}_{\mathrm{w}}$ adalah $9,31 \mathrm{~m}$. Waktu tempuh gelombang tsunami tercepat juga berada di daerah Mana dalam waktu 20 menit 7 detik.

\section{DAFTAR PUSTAKA}

Ardiansyah, S., "Model Prakiraan Kejadian Gempa Bumi di Daerah Bengkulu", (BMKG, Kepahing, 2014), hal 137-146

BMKG, "Katalog Gempa Bumi Signifikan dan Merusak 1821-2013", (BMKG, Jakarta, 2014), hal 40-41

Natawidjaja, D.H., "Gempa Bumi dan Tsunami di Sumatera dan Upaya Untuk Mengembangkan Lingkungan Hidup Yang Aman Dari Bencana Alam”, Laporan KHL, LIPI, 2007

Pribadi, S., "Pemodelan Tsunami untuk Peringatan Dini BMG", (BMKG, Jakarta, 2008), hal 131-147

Setyonegoro, W., Sunardi, B., Sulastri., Nugraha, J., Susilanto., “Analisis Sumber Gempa Bumi pada Segmen Mentawai (Studi Kasus: Gempa Bumi 25 Oktober 2010)", (BMKG, Jakarta, 2012), hal 139-148

Sunarjo., Gunawan, M. T., Pribadi, S., "Gempa Bumi Edisi Populer”, (BMKG, Jakarta, 2010), hal 197-199

NOAA., National Center For Information Enviromental Information, http://www.noaa.gov/, (diakses 12 April 2016)

USGS., Significant Earthquake Archive, http://www.usgs.gov/, (diakses 12 April 2016) 